\title{
Pengaruh Motivasi Kerja, Kompetensi Dan Kepuasan Kerja Terhadap Kinerja Pegawai Pada Upt Balai Kph Ampang Riwo Soromandi Dinas Lingkungan Hidup Dan Kehutanan Provinsi Nusa Tenggara Barat
}

\section{(Influence of work motivation, employee competence and work satisfaction on the performance of Ampang Riwo Soromandi Forest Management Unit, Environment dan Forestry Office Province of NTB)}

\author{
Muzakir ${ }^{1}$ Surati $^{2}$, Achmad Fauzi $^{3}$ \\ Program Studi Manajemen Sumber Daya Manusia
}

\begin{abstract}
Abstrak
Kinerja adalah hasil kerja dari pegawai baik kualitas maupun kuantitas dalam suatu periode tertentu dalam melaksanakan tugas kerjanya sesuai tanggungjawab diberikan kepadanya. Untuk mencapai hasil kerja tersebut, terdapat beberapa faktor yang mentukan diantaranya adalah motivasi kerja, kompetensi pegawai, dan kepuasan kerja. Dari hasil pengamatan penulis terhadap fenomena yang terjadi pada UPT Balai KPH Ampang Riwo Soromandi Dinas Lingkungan Hidup dan Kehutanan Provinsi NTB bahwa terdapat banyak dinamika yang berhubungan dengan kinerja pegawai diantaranya tingkat kehadiran pegawai, aktivitas harian pegawai, kondisi lingkungan, serta kemampuan pegawai melaksanakan tugas dan tanggung jawabnya. Berdasarkan hasil penelitian sebelumnya menunjukan adanya pengaruh faktor motivasi, kompetensi, kepuasan terhadap kinerja. Tetapi ada juga hasil penelitian yang tidak menunjukan adanya pengaruh tersebut. Oleh karena penelitian ini merupakan upaya untuk membuktikan apakah memang ada pengaruh motivasi kerja, kompetensi pegawai dan kepuasan kerja kinerja pegawai pada UPT Balai KPH Ampang Riwo Soromandi Dinas Lingkungan Hidup dan Kehutanan Provinsi NTB. Responden dalam penelitian ini menggunakan seluruh populasi pegawai sebanyak 72 responden. Analisis data menggunakan analisis statistik regresi linier berganda dengan aplikasi SPSS. Hasil penelitian menunjukkan bahwa secara parsial maupun simultan variabel Motivasi Kerja, Kompetensi Pegawai, dan Kepuasan berpengaruh positif dan signifikan terhadap kinerja pegawai pada UPT Balai KPH Ampang Riwo Soromandi Dinas Lingkungan Hidup dan Kehutanan Provinsi NTB.
\end{abstract}

Kata Kunci : Pengaruh Motivasi Kerja, Kompetensi Pegawai, dan Kepuasan Kerja terhadap kinerja pegawai

\section{Abstract}

Performance is the result of employees work both quality and quantity within a certain period of time in carrying out their work duties in accordance with the responsibilities given to them. To achieve the results of the work, there are several factors that ifluenced it includingwork motivation, employee competence, and employee work satisfaction. From the writer's observation of the phenomenon that occurs in the Ampang Riwo Soromandi Forest Management Unit, Environment dan Forestry Office Province of NTB, there are many dynamics related to employee performance including employee attendance, daily activities, environmental conditions, and the ability of employees to carry out their duties and responsibilities. Based on the results of previous studies indicate the influence of motivation, competence, and satisfaction factors on performance. But there are also research results that do not show the influence between those factors. Because this research is an attempt to prove whether there is indeed an influence of work motivation, employee competence and work satisfaction on the performance of Ampang Riwo Soromandi Forest Management Unit, Environment dan Forestry Office Province of NTB staff. Respondents in this study used an entire population of 72 respondents. Data analysis used multiple linear regression statistical analysis with the SPSS application. The results showed that partially or simultaneously variables of Work 
Motivation, Employee Competence and Work Satisfaction had a positive and significant effect on employee performance in the Ampang Riwo Soromandi Forest Management Unit Environment dan Forestry Office Province of NTB.

Keywords: The influence of Work Motivation, Employee Competence and Work Satisfaction on employee performance

\section{PENDAHULUAN}

Sumber daya manusia merupakan aset penting karena manusia merupakan sumber daya yang dinamis dan selalu dibutuhkan dalam setiap proses produksi barang maupun jasa (Sudarmanto, 2012). Organisasi yaitu Perangkat Daerah yang merupakan penggerak utama dalam mendukung pembangunan suatu daerah. Bentuk dan tujuan organisasi, digerakan oleh Kinerja Sumber Daya Manusia yang dimilikinya. Kinerja Sumber Daya Manusia sangat terpengaruh oleh motivasi kerja, berbagai visi dirancang untuk kepentingan manusia dimana dalam pelaksanaan misinya dikelola dan diurus oleh manusia. Ini berarti, bahwa manusia merupakan sumber daya strategis dalam semua aktivitas organisasi. Kinerja atau performa kerja yang baik dapat menjadi keistimewaan tersendiri bagi sebuah daerah. Istilah kinerja didefinisikan sebagai prestasi atau hasil kerja (output) baik kualitas maupun kuantitas yang dicapai oleh seorang pegawai dalam melaksanakan tugas kerjanya sesuai dengan tanggungjawab yang diberikan (Mangkunegara, 2011).

Pegawai yang memiliki motivasi kerja yang tinggi, dilengkapi dengan kompetensi kerja yang memenuhi standar kerja dan didukung oleh kepuasan kerja adalah serangkaian factor penentu tinggi rendahnya pencapaian kinerja suatu organisasi, takter kecuali bagi Unit Pelayanan Terpadu (UPT) Balai Kesatuan Pengelolaan Hutan (BKPH) Ampang Riwo Soromandi DisLHK Provinsi Nusa Tenggara Barat (NTB). Berdasarkan LAKIP Balai Kesatuan Pengelolaan Hutan (BKPH) Ampang Riwo Soromandi DisLHK Prov. NTB Tahun (2018) bahwa terjadinya penurunan kualitas lingkungan hidup menjadi salah satu permasalahan utama. Dalam beberapa tahun terakhir, nilai indeks Kualitas Lingkungan Hidup (IKLH) yang dicapai oleh Provinsi NTB berdasar oleh Kementerian
Lingkungan Hidup dan Kehutanan secara umum belum memenuhi target yang telah ditetapkan. Potensi yang mempengaruhi capaian nilai IKLH meliputi industri makanan dan minuman, bahan bangunan, perhiasan, logam, perkebunan, permukiman, pertambangan, pertanian, peternakan, industri pariwisata, jumlah kendaraan, limbah padat sarana transportasi, beban limbah cair dan limbah B3 dari sarana penginapan serta rumah sakit, keterbatasan fasilitas buang air besar, serta timbunan sampah.

Berdasarkan latar belakang diatas maka penelitian yang berjudul Pengaruh Motivasi Kerja, Kompetensi Dan Kepuasan Kerja Terhadap Kinerja Pegawai Pada Upt Balai Kph Ampang Riwo Soromandi Dinas Lingkungan Hidup Dan Kehutanan Provinsi Nusa Tenggara Barat. ini penting untuk dilakukan untuk menjawab kebutuhan akan data-data yang telah disebutkan di atas.

Tujuan dari penelitian ini adalah :

1. Menganalisis pengaruh motivasi kerja terhadap kinerja pegawai pada UPT Balai Kesatuan Pengelolaan Hutan (BKPH) Ampang Riwo Soromandi DisLHK Prov NTB.

2. Menganalisis pengaruh kompetensi terhadap kinerja pegawai pada UPT Balai Kesatuan Pengelolaan Hutan (BKPH) Ampang Riwo Soromandi DisLHK Prov NTB.

3. Menganalisis pengaruh kepuasan kerja terhadap kinerja pegawai pada UPT Balai Kesatuan Pengelolaan Hutan (BKPH) Ampang Riwo Soromandi DisLHK Prov NTB.

4. Menganalisis pengaruh simultan motivasi, kompetensi dan kepuasan kerja terhadap kinerja pegawai pada UPT Balai Kesatuan Pengelolaan Hutan (BKPH) Ampang Riwo Soromandi DisLHK Prov NTB. 


\section{METODE}

Penelitian ini dilaksanakan pada pegawai UPT Balai Kesatuan Pengelolaan Hutan (BKPH) Ampang Riwo Soromandi, metode yang digunakan dalam penelitian ini adalah metode Analisis Deskriptif. Metode Analisis Deskriptif adalah analisis yang dilakukan berdasarkan jawaban yang diperoleh dari responden dalam bentuk keteranganketerangan dan bukan dalam dalam bentuk angka. Dalam hal ini meliputi karakteristik responden terhadap variabel yang dinilai. Untuk mengetahui tanggapan responden terhadap variabel yang dinilai, digunakan Skala likert, dimana responden menyatakan tingkat setuju atau tidak setuju (baik atau tidak baik) mengenai berbagai pernyataan tentang prilaku, objek, orang, atau kejadian. Menurut Sugiyono (2010:137).

Dalam tahap Tahap pengumpulan data dilakukan untuk memperoleh data yang berguna untuk pemecahan permasalahan yaitu

1. Data Primer adalah Jenis data ini diperoleh melalui kunjungan langsung atau survei yang dilakukan dilokasi penelitian, terhadap obyek yang diteliti dan dipandu dengan kuesioner.

2. Data Sekunder adalah data penelitian yang diperoleh secara tidak langsung melalui media perantara berupa visi dan misi organisasi, dan gambaran umum lain menyangkut organisasi sebagaimana ketentuan/peraturan yang berhubungan dengan penelitian.

Kuesioner dikembangkan berdasarkan konsepsi dasar dari teori yang melandasi dari variabel-variabel penelitian. Kuesioner bertujuan untuk mengungkap data tentang motivasi kerja, kompetensi kerja, kepuasan kerja dan kinerja pegawai pada UPT Balai Kesatuan Pengelolaan Hutan (BKPH) Ampang Riwo Soromandi DisLHK Prov NTB. Kuesioner disusun dan dikembangkan berdasarkan dalam jabaran operasionalisasi variabel penelitian.
Tabel 3.1Jabaran Operasional Variabel Penelitian

\begin{tabular}{|c|c|c|c|}
\hline No & Variabel & Indikator & ItemKuesioner \\
\hline 1 & $\begin{array}{l}\text { Motivasi Kerja } \\
\text { (Y) }\end{array}$ & $\begin{array}{l}\text { 1. Kebutuhan Akan Prestasi } \\
\text { 2. Kebutuhan Akan Kekuasaan } \\
\text { 3. Kebutuhan Akan Afiliasi }\end{array}$ & $\begin{array}{l}1,2,3,5,6,7,8,9 \text {, } \\
10 .\end{array}$ \\
\hline 2 & $\begin{array}{l}\text { Kompetensi } \\
\text { Kerja } \\
\text { (X3) }\end{array}$ & $\begin{array}{l}\text { 1. Pengetahuan (knowledge) } \\
\text { 2. Keterampilan } \\
\text { 3. Sikap professional }\end{array}$ & $\begin{array}{l}1,2,3,5,6,7,8,9, \\
10 .\end{array}$ \\
\hline 3 & $\begin{array}{l}\text { KepuasanKerja } \\
\text { (X1) }\end{array}$ & $\begin{array}{l}\text { 1. Kepuasan terhadap gajidantunjangan } \\
\text { 2. Kepuasan terhadap rekan kerja } \\
\text { 3. Kepusanterhadaatasan }\end{array}$ & $1,2,3,5,6,7,8,9,10$ \\
\hline 4 & $\begin{array}{l}\text { KinerjaPegawai } \\
(\mathrm{Y})\end{array}$ & $\begin{array}{l}\text { 1. KualitasKerja } \\
\text { 2. KuantitasKerja } \\
\text { 3. Tanggungjawab }\end{array}$ & $\begin{array}{l}1,2,3,5,6,7,8,9 \text {, } \\
10 .\end{array}$ \\
\hline
\end{tabular}

Sumber : Pengolahan metode peneliti

Untuk mengetahui tanggapan responden terhadap variabel yang dinilai, digunakan Skala likert, dimana responden menyatakan tingkat setuju atau tidak setuju (baik atau tidak baik) mengenai berbagai pernyataan tentang prilaku, objek, orang, atau kejadian. Menurut Sugiyono (2010:137), Skala Likert digunakan untuk mengukur sikap, pendapat, dan prestasi seseorang atau sekelompok orang tentang fenomena sosial, di mana dalam penelitian fenomena sosial telah ditetapkan secara spesifik oleh peneliti yang disebut variabel penelitian. Untuk setiap alternatif jawaban yang diberikan diberikan bobot sebagai berikut :

Tabel 3.2 Penskoran Item Instrumen Penelitian

\begin{tabular}{|c|l|c|}
\hline No & Pilihan Jabawan & Skor \\
\hline 1 & Sangat Setuju & 5 \\
\hline 2 & Setuju & 4 \\
\hline 3 & Cukup Setuju & 3 \\
\hline 4 & Kurang Setuju & 2 \\
\hline 5 & Tidak Setuju & 1 \\
\hline
\end{tabular}

Sumber: Pengolahan metode peneliti

Nilai rata-rata atau mean masingmasing variabel dimasukkan ke dalam kelaskelas dengan interval tertentu. Interval kelas tersebut diperoleh dengan rumus sebagai berikut :

$$
=\frac{\begin{array}{c}
\text { Interval Kelas } \\
\text { Nilai Tertinggi }- \text { Nilai Terendah }
\end{array}}{\text { Jumlah Kelas }}
$$

Interval tersebut dijadikan pedoman untuk menentukan batas bawah dan batas atas setiap kelas, yang akhirnya kelas-kelas tersebut digunakan untuk memasukkan nilai rata-rata masing-masing variabel penelitian. 


\section{HASIL DAN PEMBAHASAN}

Berdasarkan hasil pendataan Secara umum ada beberapa karakteristik responden yaitu:

1. Karakteristik responden dapat diklasifikasikan dalam kelompok Jenis Kelamin sebagimana yang ditampilkan pada tabel berikut.

Tabel 4.1 Jumlah Responden Berdasarkan Jenis Kelamin

\begin{tabular}{|c|c|c|}
\hline $\begin{array}{c}\text { Jenis } \\
\text { Kelamin }\end{array}$ & Frekuensi & $\begin{array}{c}\text { Persentase } \\
(\mathbf{\%})\end{array}$ \\
\hline Laki-laki & 63 & 87 \\
\hline Perempuan & 9 & 13 \\
\hline Jumlah & $\mathbf{7 2}$ & $\mathbf{1 0 0}$ \\
\hline
\end{tabular}

Sumber: Lampiran II, data diolah peneliti

Berdasarkan tabel diatas responden yang menjadi objek dalam penelitian ini memiliki jenis kelamin yang berbeda. Sejumlah responden memiliki jenis kelamin laki-laki lebih banyak dibandingkan dengan responden yang berjenis kelamin perempuan yaitu responden laki-laki berjumlah 63 orang atau $87 \%$ dan perempuan berjumlah9orang atau $13 \%$.

2. Karakteristik responden yang menjadi objek dalam penelitian dapat diklasifikasikan dalam kelompok usia. Sebagaimana data Karakteristrik sebagai berikut.

Tabel 4.2Jumlah Responden Berdasarkan Usia

\begin{tabular}{|c|c|c|c|}
\hline \multirow{2}{*}{$\mathbf{N}$} & \multirow{2}{*}{$\begin{array}{c}\text { Keteranga } \\
\text { n }\end{array}$} & \multicolumn{2}{|c|}{ Jumlah } \\
\cline { 3 - 4 } & & $\begin{array}{c}\text { Frekuens } \\
\mathbf{i}\end{array}$ & $\begin{array}{c}\text { Perse } \\
\mathbf{n}\end{array}$ \\
\hline 1 & $\leq 30$ th & 2 & 3 \\
2 & $31-40$ th & 21 & 29 \\
3 & $41-50$ th & 47 & 65 \\
4 & $\geq 51$ th & 2 & 3 \\
\hline \multicolumn{2}{|c|}{ Jumlah } & $\mathbf{7 2}$ & $\mathbf{1 0 0}$ \\
\hline
\end{tabular}

Sumber: Lampiran II, data diolah peneliti

Tabel tersebut di atas menjelaskan bahwa secara rata mayoritas responden berada pada rentang usia 41-50 tahun sebanyak 47orang dengan persentase $65 \%$, sedangkan rentang usia $\leq 30$ berjumlah 2 orang dengan persentase $3 \%$ dan rentang usia $\geq 51$ tahun sebanyak 2 orang dengan persentase $3 \%$. Responden dengan rentang usia 31-40 tahun sebanyak 21 orang dengan persentase $29 \%$.

3. Responden memiliki jenjang pendidikan terakhir yang heterogen (beragam). Setelah melalui hasil penelitian diketahui tingkat pendidikan terakhir responden berikut ini :

Tabel 4.3 Responden Berdasarkan Pendidikan Terakhir

\begin{tabular}{|c|c|c|c|}
\hline No & Pendidikan & Frekuensi & $\begin{array}{c}\text { Persentase } \\
(\mathbf{\%})\end{array}$ \\
\hline 1 & S2 & 1 & 2 \\
\hline 2 & S1 & 45 & 62 \\
\hline 3 & Diploma & 2 & 3 \\
\hline 4 & SMA & 24 & 33 \\
\hline \multicolumn{2}{|c|}{ Jumlah } & $\mathbf{7 2}$ & $\mathbf{1 0 0}$ \\
\hline
\end{tabular}

Sumber: Lampiran II, data diolah peneliti

Menunjukkan bahwa responden didominasi oleh berpendidikan terakhir pada jenjang Srata Satu (S1) dengan jumlah paling banyak yaitu sebanyak 44orang atau $62 \%$, dan yang terendah adalah dengan tingkat pendidikan terakhir SMA sebanyak 24 orang atau 33\%. Responden dengan pendidikan terakhir Diploma berjumlah 2 orang atau 3\%, responden S2 sebanyak 1 orang atau $2 \%$.

4. Bagian yang diteli dalam penelitian ini adalah termasuk masa kerja responden yang dapat dilihat pada tabel di bawah ini:

Tabel 4.4 Jumlah Responden BerdasarkanMasa Kerja

\begin{tabular}{|c|c|c|c|}
\hline \multirow{2}{*}{ No } & \multirow{2}{*}{ Keterangan } & \multicolumn{2}{|c|}{ Jumlah } \\
\hline & & Frekuensi & $\%$ \\
\hline 1 & $\leq 5$ tahun & 2 & 3 \\
\hline 2 & 6-10 tahun & 13 & 18 \\
\hline 3 & 11-15 tahun & 7 & 10 \\
\hline 4 & 16-20 tahun & 9 & 12 \\
\hline 5 & $\geq 21$ tahun & 41 & 57 \\
\hline & Jumlah & 72 & 100 \\
\hline
\end{tabular}

Pada tabel di atas bahwa responden dengan masa kerja $\leq 5$ tahun sebanyak 2orang atau 3\%, sedangkan responden dengan masa kerja 6-10 tahun sebanyak 13 orang atau $18 \%$, responden dengan masa kerja 11-15 tahun sebanyak 7 orang atau $10 \%$, responden dengan masa kerja 16-20 tahun sebanyak 9 orang atau $12 \%$ dan $\geq 21$ tahun sebanyak 41 atau 57\%. 
Dalam analisis ini menggunakan langkah-langkah analisis dengan menghitung nilai harapan tertinggi dikurangi dengan nilai harapan terendah dan dibagi dengan skor tertingi per-item kuesioner, hasilnya adalah jumlah rentang kelas (kelas interval).

1. Jumlah item hasil kuesioner variabel motivasi kerja diketahui kelas interval dalam analisis deskriptif data variabel motivasi kerja dalam penelitian ini sebagai berikut.

Tabel 4.12 Deskriptif Variabel Motivasi Kerja

\begin{tabular}{|c|c|c|c|}
\hline Kelas nterval & Frekuensi & Persen & Kategori \\
\hline $12-21$ & 0 & 0,0 & Rendah \\
\hline $22-32$ & 18 & 25,0 & $\begin{array}{c}\text { Cukup } \\
\text { Tinggi }\end{array}$ \\
\hline $33-43$ & 51 & 70,8 & Tinggi \\
\hline $45-60$ & 3 & 4,2 & $\begin{array}{c}\text { Sangat } \\
\text { Tinggi }\end{array}$ \\
\hline Total & 72 & 100 & \\
\hline
\end{tabular}

Sumber: Lampiran III, data diolah peneliti

Di atas terdapat 18 orang dengan nilai persentase $25 \%$ berkategori cukup tinggi dalam motivasi kerja, 51orang dengan nilai persentasenya 70,8\% berkategori tinggi, dan 3 orang dengan nilai persentasenya $4,2 \%$ berkategori sangat tinggi.

2. Jumlah item hasil kuesioner variabel kompetensi analisis deskriptif data kompetensi responden penelitian ini sebagai berikut.

Tabel 4.13 Deskriptif Variabel Kompetensi

\begin{tabular}{|c|c|c|l|}
\hline $\begin{array}{c}\text { Kelas } \\
\text { interval }\end{array}$ & Frekuensi & Persen & Kategori \\
\hline $10-18$ & 0 & 0,0 & Rendah \\
\hline $19-26$ & 20 & 27,8 & $\begin{array}{l}\text { Cukup } \\
\text { Tinggi }\end{array}$ \\
\hline $32-41$ & 39 & 54,2 & Tinggi \\
\hline $42-50$ & 13 & 18,1 & $\begin{array}{l}\text { Sangat } \\
\text { Tinggi }\end{array}$ \\
\hline Total & 72 & 100 & \\
\hline
\end{tabular}

Sumber: Lampiran III, data diolah peneliti

Hasil analisis deskriptif dalam tabel tersebut di atas menunjukkan bahwa menurut pendapat responden tentang kompetensi kerja khususnya pengetahuan, keterampilan dan sikap pegawai sebagian besar tergolong pada kategori tinggi yaitu $54,2 \%$.

3. Jumlah item hasil kuesioner variabel kepuasan kerja dalam analisis deskriptif data Kepuasan kerja responden sebagai berikut.

Tabel 4.14 Deskriptif Variabel Kepuasan Kerja

\begin{tabular}{|c|c|c|l|}
\hline $\begin{array}{c}\text { Kelas } \\
\text { Interval }\end{array}$ & Frekuensi & Persen & Kategori \\
\hline $10-18$ & 0 & 0,0 & Rendah \\
\hline $19-26$ & 24 & 33,3 & $\begin{array}{l}\text { Cukup } \\
\text { Tinggi }\end{array}$ \\
\hline $32-41$ & 41 & 56,9 & Tinggi \\
\hline $42-50$ & 7 & 9,7 & $\begin{array}{l}\text { Sangat } \\
\text { Tinggi }\end{array}$ \\
\hline Total & 72 & 100 & \\
\hline
\end{tabular}

Sumber: Lampiran III, data diolah peneliti

Hasil analisis deskriptif dalam tabel

tersebut di atas menunjukkan bahwa menurut responden, kepuasan kerja pegawai khususnya Rekan Kerja, Lingkungan Kerja dan Terhadap Pimpinan sebagian besar tergolong pada kategori tinggi yaitu 56,9\%.

4. Jumlah item hasil kuesioner variabel kinerja pegawai dalam analisis deskriptif data penelitian sebagai berikut.

Tabel 4.15 Deskriptif Variabel Kinerja

\begin{tabular}{|c|c|c|l|}
\hline Kelas Interval & Frekuensi & Persen & Kategori \\
\hline $10-18$ & 0 & 0,0 & Rendah \\
\hline $19-26$ & 5 & 6,9 & $\begin{array}{l}\text { Cukup } \\
\text { Tinggi }\end{array}$ \\
\hline $32-41$ & 42 & 58,3 & Tinggi \\
\hline $42-50$ & 25 & 34,7 & $\begin{array}{l}\text { Sangat } \\
\text { Tinggi }\end{array}$ \\
\hline Total & 72 & 100 & \\
\hline
\end{tabular}

Sumber: Lampiran III, data diolah peneliti

Hasil analisis deskripti dalam tabel tersebut di atas menunjukkan bahwa hasil dari penelitian responden tantang kinerja pegawai khususnya pada Kualitas Kerja, Tanggung Jawab dan Kuantitas Kerja sebagian besar tergolong pada kategori tinggi yaitu 58,3\%.

Sebagaimana telah diketahui bahwa kinerja pegawai pada UPT Balai Kesatuan Pengelolaan Hutan (BKPH) 
Ampang Riwo Soromandi DisLHK Prov NTB tergolong sesuai dengan standar yang telah ditetapkan sebelumnya yaitu tinggi. Ini menunjukkan anggapan responden yang berkaitan adalah hasil kerja yang dicapai oleh pegawai dalam melaksanakan tugasnya sesuai dengan tanggung jawab meliputi kualitas, kuantitas dan tanggungjawab.

Setelah dilakukan perhitungan Uji-F diketahui bahwa taraf signifikan 0,00 , lebih kecil 0,05.F-Hitung $=16.514,57>$ F-tabel $=$ 2.450 artinya hipotesis nihil (H0) ditolak dan hipotesis alternatif (Ha) berbunyi "ada pengaruh simultan yang signifikan motivasi, kompetensi dan kepuasan kerja terhadap kinerja pegawai pada UPT Balai Kesatuan Pengelolaan Hutan (BKPH) Ampang Riwo Soromandi DisLHK Prov NTB" diterima

Tabel 4.17. Penjelasan Persamaan Regresi

\begin{tabular}{|c|c|}
\hline Simbol & Penjelasan \\
\hline$A$ & $\begin{array}{l}\text { Mengisyaratkan bahwa jika dalam melaksanakan tugas dan tangoung ji } \\
\text { sebagai pegawai pada UPT Balai Kesatuan Pengelolaan Hutan (BK } \\
\text { Ampang Riwo Soromandi DisLHK Prov NTB tidak memiliki moti } \\
\text { kompetenni dan kepuasan kerja maka kinerja pegawai sebesar 0,362. }\end{array}$ \\
\hline$b_{1} X_{1}$ & 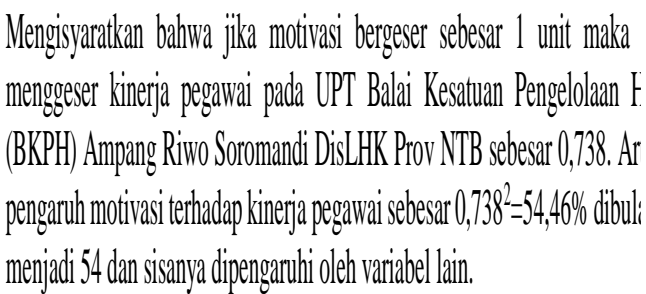 \\
\hline$b_{2} X_{2}$ & 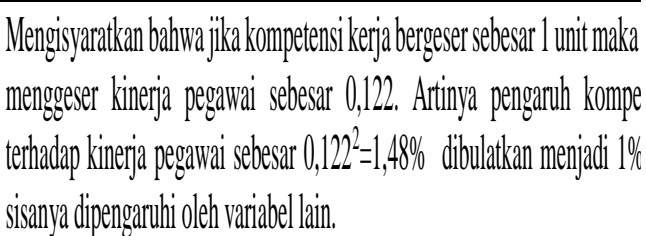 \\
\hline$b_{3} X_{3}$ & 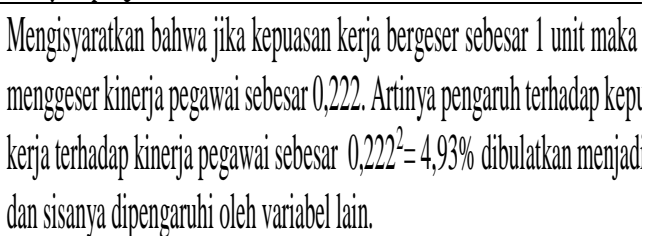 \\
\hline
\end{tabular}

Sumber: Lampiran IV, data diolah peneliti

Model Persamaan Regresi:

$$
\begin{aligned}
' \mathrm{Y} & =\alpha(0,362)+b 1 \mathrm{X} 1(0.738)+b 2 \mathrm{X} 2(0.122) \\
& +b 3 \mathrm{X} 3(0.222)
\end{aligned}
$$

Hasil penelitian dengan menggunakan analisis deskriptif diketahui bahwa motivasi kerja pegawai pada UPT Balai Kesatuan Pengelolaan Hutan (BKPH) Ampang Riwo
Soromandi DisLHK Prov NTB tergolong tinggi. Artinya keinginan untuk melakukan sebagai kesediaan untuk mengeluarkan tingkat upaya yang tinggi untuk tujuan-tujuan organisasi, yang dikondisikan oleh kemampuan upaya itu untuk memenuhi suatu kebutuhan. Motivasi merupakan dorongan, upaya dan keinginan yang ada pada diri manusia yang akan mengarahkan perilaku untuk melakukan tugas atau pekerjaan dengan baik, sedangkan kepuasan merupakan sikap yang menunjukkan adanya kesesuaian antara harapan dan hasil yang didapatkan. Tinggi rendahnya motivasi kerja mengindikasikan maju mundur suatu organisasi. Pegawai yang memiliki moitvasi kerja yang tinggi adalah modal bagi suatu lembaga agar dapat mewujudkan kinerja sesuai dengan standar yang telah ditentukan (Robins dan Judge 2010).

\section{Kesimpulan}

Berdasarkan hasil penelitian dan pembahasan maka sampailah pada tahap penarikan kesimpulan penelitian, yaitu:

1. Motivasi kerja memiliki pengaruh positif dan signifikan terhadap kinerja pegawai pada UPT Balai Kesatuan Pengelolaan Hutan (BKPH) Ampang Riwo Soromandi DisLHK Prov NTB. Ini menjelaskan semakin tinggi motivasi maka semakin tinggi pula kinerja pegawai.

2. Kompetensi memiliki pengaruh positif dan signifikan terhadap kinerja pegawai pada UPT Balai Kesatuan Pengelolaan Hutan (BKPH) Ampang Riwo Soromandi DisLHK Prov NTB. Semakin baik kompetensi maka akan semakin ahli dalam bekerja yang pada gilirannya akan dapat meningkatkan kinerjanya.

3. Kepuasan kerja berpengaruh positif dan signifikan terhadap kinerja pegawai pada UPT Balai Kesatuan Pengelolaan Hutan (BKPH) Ampang Riwo Soromandi DisLHK Prov NTB. Semakin senang seseorang terhadap pekerjaan, gaji dan rekan kerja maka akan meningkatkan kinerja.

4. Secara bersama-sama motivasi, kompetensi dan kepuasan kerja memiliki pengaruh signifikan terhadap kinerja pegawai pada UPT Balai Kesatuan 
Pengelolaan Hutan (BKPH) Ampang Riwo Soromandi DisLHK Prov NTB.

\section{Saran}

Berdasarkan kesimpulan hasil penelitian di atas maka ada beberapa saran yang perlu disampaikan oleh peneliti, yaitu:

1. Bagi Pemerintah Daerah harus lebih memperhatikan kondisi kerja dan kinerja pegawai pada UPT Balai Kesatuan Pengelolaan Hutan (BKPH) Ampang Riwo Soromandi DisLHK Prov NTB mengingat tantangan yang semakin hari semakin besar maka dibutuhkan motivasi, kompetensi dan kepuasan kerja pegawai karena terbukti baik secara parsial maupun secara bersama-sama (simultan) mempengaruhi kinerja.

2. Bagi pegawai pada UPT Balai Kesatuan Pengelolaan Hutan (BKPH) Ampang Riwo Soromandi DisLHK Prov NTB agar mempertahankan dan meningkatkan lagi semangat dan kompetensi kerja serta kepuasan kerja agar menghasilkan kualitas dan kuantitas kerja sesuai dengan yang diharapkan.

3. Bagi peneliti lain yang melakukan penelitian serupa agar dapat mengkaji lebih luas dan dalam lagi mengenai faktor-faktor yang mempengaruhi motivasi, kompetensi, kepuasan kerja dan kinerja pegawai dalam menjalankan tugas muliannya dengan pendekatan penelitian kaulititatif.

\section{DAFTAR RUJUKAN}

Agung Gita Subakti. 2013. Pengaruh Motivasi, Kepuasan, Dan Sikap Kerja Terhadap Kinerja Karyawan Di Café X Bogor. Journal Binus Business Review Vol. 4 No. 2 November 2013: 596-606. https://media.neliti.com/media/publica tions/167877-ID-pengaruh-motivasikepuasan-dan-sikap-ker.pdf.

Alamdar Hussain Khan dan Muhammad Musarrat Nawaz. 2013. Impact Of Job Satisfaction On Employee Performance: An Empirical Study Of Autonomous Medical Institutions of Pakistan. African Journal of Business Management Vol. 6 (7), pp. 2697-2705, 22 February, 2013 Available online at http://www.academicjournals.org/AJB M.
Arun Kumar. 2014. An Empirical Study: Relationship between Employee Motivation, Satisfaction and Organizational Commitment. Int. J. Manag. Bus. Res., 4 (2), 81-93, Spring 2014.

Arif Yusuf, S. 2016. Pemahaman Manajemen sumber daya manusia, Yokyakarta: CAPS (Canter for Academic Publishing Service).

Darmawan dan Hubeis. 2015. Pengaruh Kompetensi, Motivasi dan Kepuasan Kerja Terhadap Kinerja Karyawan Di $\mathrm{Pt}$ Elnusa Tbk. Jurnal Ekonomi. https://ejurnal.esaunggul.ac.id/index.p $\mathrm{hp} /$ Eko/issue/view/270.

Hasibuan Malayu, S.P. 2010. Manajemen Sumber Daya Manusia. Cetakan ke-11. Jakarta: PT.Bumi Aksara.

Handoko, T.H. 2011. Meningkatkan Produktivitas Karyawan. Bandung: PT. Kineka Cipta.

Ida Ayu Oka Martini dan Ketut Rahyuda. 2018. The Influence of Competency on Employee Performance through Organizational Commitment Dimension. OSR Journal of Business and Management (IOSR-JBM) e-ISSN: 2278-487X, p-ISSN: 2319-7668. Volume 20, Issue 2.

Jerome dan Ayooluwa. 2019. Relationship Between Motivation And Job Satisfaction Of Staff In Private University Libraries, Nigeria. Academy of Strategic Management Journal. Volume 18, Issue 1, 2019.

Lubis, Satria Hadi. (2016). Aspek-aspek Etos Kerja dan Faktor-faktor yang Mempengaruhinya.

(http://www.SatriaHadiLubis/aspekaspek-etos-kerja-dan -faktor-faktoryang-mempengaruhi.

Mathis, Robert L dan Jackson, John H. 2012. Human Resource Management alih bahasa. Jakarta : Salemba Empat.

Mahsun, M., Sulistiyowati, F., Purwanugraha, H.A. 2011. Akuntansi Sektor Publik. Edisi Ketiga. Yogyakarta. BPFE.

Mangkunegara, A.P. 2011. Manajemen

Sumber Daya Manusia Perusahaan. Bandung: Refika Aditama. 
Terakreditasi Peringkat 4 (No. SK: 36/E/KPT/2019)

Mohammed Inuwa. 2016. Job Satisfaction and Employee Performance: An Empirical Approach. The Millennium University Journal; Vol. 1, No. 1; 2016 ISSN 2225-2533 Published by The Millennium University.

Murgianto dan Sulasmi. 2016. The Effects Of Commitment, Competence, Work Satisfaction On Motivation, And Performance Of Employees At Integrated Service Office Of East Java. International Journal of Advanced Research (2016), Volume 3, Issue -378396

Nur Abidin. 2013. Pengaruh Kepuasan, Motivasi dan Kedisiplinan Kerja Terhadap Kinerja Pegawai Di Lingkungan Kantor Wilayah Departemen Agama Provinsi Jawa Tengah. Tesis Program Pascasarjana Universitas Dian Nuswantoro Semarang. http://eprints.dinus.ac.id/15056/1/JUR NAL_TESIS.pdf. Diakses 26 Okbtober 2019.

Nnaeto Japhet Olusadum dan Ndoh Juliet Anulika. 2018. Impact of Motivation on Employee Performance: A Study of Alvan Ikoku Federal College of Eduaction. Journal of Management and Strategy Vol. 9, No. 1; 2018.

Rijalu dan Zewude (2014) The effect of compensation on employees motivation: In Jimma University academic staff. Basic Research Journal of Business Management and Accounts ISSN 2315-6899 Vol. 3(2) pp. 17-27 February 2014. http//www.basicresearchjournals.org. 